Nigeria Journal of Pure and Applied Physics

Vol. 10(1), 12 - 15, 2020

CPhysics Department, Federal University of Technology Akure

DOI: $\underline{10.4314 / \text { njpap.v10i1.3 }}$

\title{
Thermal Response at Room Temperature and Device Applications of Two Wood Species in Akure, South Western Nigeria
}

\author{
M. A. Adekoya ${ }^{\dagger 1,2}$, A. O. Adelakun ${ }^{2}$, A. A. Faremi ${ }^{3}$, S. S. Oluyamo ${ }^{2}$ \\ ${ }^{1}$ Department of Physics, Edo University Iyamho, Edo State, Nigeria \\ ${ }^{2}$ Condensed Matter and Statistical Physics Research Unit, Department of Physics, Federal University of Technology, Akure,
} Nigeria

${ }^{3}$ Department of Physics, Federal University, Oye-Ekiti, Ekiti State, Nigeria

${ }^{\dagger}$ Corresponding Author’s Email: mathewadekoya14@gmail.com

\begin{abstract}
Thermal properties (Density, Thermal conductivity and Specific heat capacity) play important impact in the formation of devices made of wooden materials. This study examines the room temperature thermal response of ten bulk samples from the species of Pterygota macrocarpa and Antiaris africana wood species found in South Western Nigeria. The samples were processed into appropriate shapes to fit into the parallel plane arrangement to determine the thermal properties. Temperature dependent models were used to obtain the specific heat capacities of the samples within a temperature variation of $308.25 \mathrm{~K}-310.00 \mathrm{~K}$. The results revealed that the thermal properties (thermal conductivities and specific heat capacities) increase as temperature increases for all the bulk samples considered. The results of the research showed that the selected wood samples could find useful applications in industrial insulating devices.
\end{abstract}

Keywords: Wood material, Lee's disc apparatus, Temperature and Thermal properties.

\section{INTRODUCTION}

The importance of wood and wood products in buildings and other areas of industrial design cannot be overemphasized. Wood is a natural organic composite material that consists of cellulose, hemicelluloses, lignin and extractives, which had been used and adapted by man since the earliest recognition that the material could be utilized for solving basic needs $[1,2]$. The performance of wood-frame depends on the thermal properties of wood and wood products $[3,4]$. Wood is a major material in building and designs whose thermal conductivity is a function of temperature, density, compacting pressure, particle sizes, moisture etc. [5,6]. Information on the thermal conductivity of wood and its relationship to other wood properties is of interest from the standpoint of thermal insulation, drying, plasticizing, preservation, gluing of wood and where heat resistance of wood is a major consideration in its application [7]. Knowledge of physical properties provides a basis for predicting how wood reacts to manufacturing forces and how it will perform in service. Some of the physical properties include; density, thermal conductivity, specific heat, particle size, porosity etc. [8]. Determination of thermal properties from wood based materials depend on several factors such as; Material structure, size, porosity, moisture content, density, the presence of a defect, temperature, and pressure etc. $[9,10]$. The flow of heat through wood sample is often a measure of the thermal properties.

This present research, however, is aimed at investigating the thermal response at room temperature and device applications of two wood species in Akure, South Western Nigeria

\section{MATERIALS AND EXPERIMENTAL PROCEDURE}

Two different wood species of the families of Moraceae and Sterculiaceae found in the rainforest region, South Western Nigeria were used in this study. These wood samples were cut into circular shape with circular saw machine. The thermal conductivities of the sample were determined using Lee's disc method.

Details of the procedure can be found in the literatures [6, $10]$ and $[11-14]$. The Thermal Conductivity $(\lambda)$ of each sample of thickness $(d)$ and radius $(r)$ were estimated using the following equations;

$$
\lambda_{w}=\frac{e d}{2 \pi r^{2}}\left[a_{S}\left(\frac{T_{A}+T_{B}}{2}\right)+2 a_{A} T_{A}\right]
$$

where $e$ is given by:

$$
e=\frac{I V}{\left[a_{A} T_{A}+a_{S}\left(\frac{T_{A}+T_{B}}{2}\right)+a_{B} T_{B}+a_{C} T_{C}\right]}
$$

where $a_{A}, a_{B}, a_{C}$ and $a_{S}$ are the exposed surface areas of discs A, B, C and the wood sample respectively. $T_{\mathrm{A}}, T_{\mathrm{B}}$ and $T_{\mathrm{C}}$ are the temperatures of the discs $\mathrm{A}, \mathrm{B}$ and $\mathrm{C}$ above ambient. $\mathrm{V}$ is the potential difference across the heater and $\mathrm{I}$ is the current which flows through it.

\subsection{Determination of Density}

The density of a substance is its mass $\left(m_{w}\right)$ per unit volume $\left(v_{w}\right)$. Mathematically, density is defined as

$$
\rho_{w}=\frac{m_{w}}{v_{w}}
$$


Table 1: Physical Properties of Pterygota macrocarpa (Bulk wood)

\begin{tabular}{|c|c|c|c|c|}
\hline Temperature & Density & Thermal & SHC & SHC \\
\hline \multirow[t]{3}{*}{ K } & $\mathrm{Kgm}^{-3}$ & Conductivity & Simpson & Koch \\
\hline & & $W m^{-1} K^{-1}$ & (Method) & (Method) \\
\hline & & & $k J k^{-1} K^{-1}$ & $k J k^{-1} K^{-1}$ \\
\hline 308.25 & 403.7 & 0.3351 & 1.2951 & 1.2651 \\
\hline 308.50 & 411.1 & 0.3398 & 1.2961 & 1.2662 \\
\hline 309.00 & 405.1 & 0.3442 & 1.2980 & 1.2684 \\
\hline 309.50 & 468.1 & 0.3468 & 1.2999 & 1.2706 \\
\hline 309.75 & 451.1 & 0.3588 & 1.3009 & 1.2717 \\
\hline
\end{tabular}

Table 2: Physical Properties of Antiaris africana (Bulk wood)

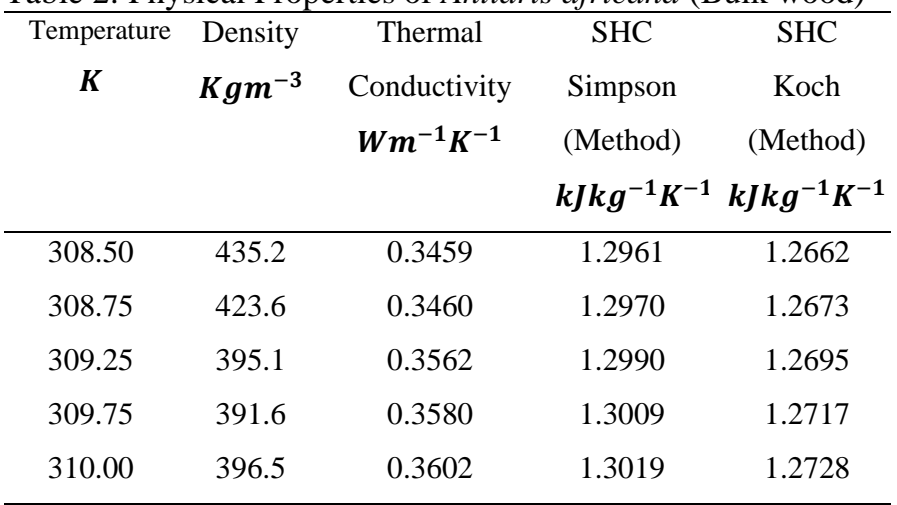

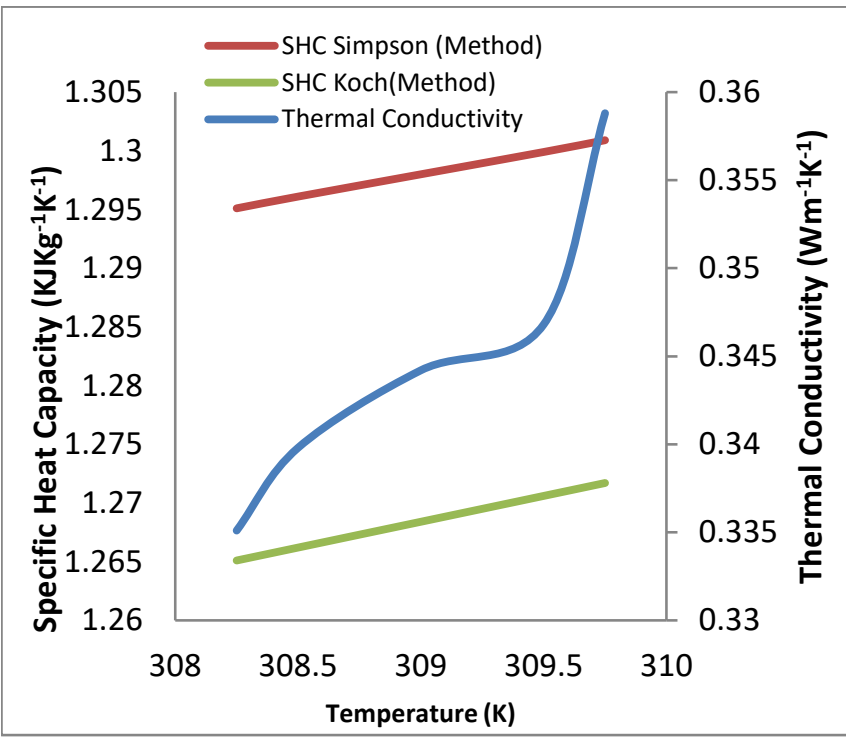

Fig. 1 Graph of Specific Heat Capacity $\left(\mathrm{kJ} \mathrm{kg}^{-1} \mathrm{~K}^{-1}\right)$ and Thermal Conductivity $\left(W m^{-1} K^{-1}\right)$ against Temperature $(\mathrm{K})$ for Pterygota macrocarpa

where mass $\left(m_{w}\right)$ and density $\left(\rho_{w}\right)$ of the wood samples were measured using digital weighing balance and weighing displacement methods [15,16].

\subsection{Determination of Specific Heat Capacity}

The specific heat of wood changes as volatiles leaves the particle and the particle temperature increases. The specific heat capacity of wood depends on the temperature and moisture content of the wood, but is practically independent of density and species. Two different models were used to determine the specific heat capacity of the bulk wood samples. The approximate specific heat capacity of oven-dry wood $c\left(\mathrm{~kJ} \mathrm{~kg}^{-1} \mathrm{~K}^{-1}\right)$ as a function of temperature $T(K)$ is given by Simpson and Tenwolde [17] as

$$
c_{w}=0.1031+0.003867 T
$$

Koch (1969) also provided a relation for the specific heat capacity at a temperature range between $333-413 \mathrm{~K}$ as

$c_{w}=0.2651+0.001004 T$

Equation (5) was modified by Grønli [8] to accommodate lower temperatures (i.e. $298-413 \mathrm{~K}$ ). The resulting relation becomes,

$$
c_{w}=-0.0912+0.0044 T
$$

where $T$ is equilibrium temperature.

The temperature range in the present study falls within $298-413 \mathrm{~K}$, hence, equation (6) was adopted to estimate the specific heat capacity of the bulk sample.

\section{RESULTS AND DISCUSSION}

The results of the analysis are presented in Tables 1-2. The thermal conductivities values for all the wood species considered increase as the temperatures increase in Figure 1 and 2. This is in agreement with Gupta et al. [18] on the Specific heat and thermal conductivity of softwood bark and softwood char particles. The thermal conductivities increase with increase in specific heat capacities for the bulk samples which conforms with Hankalin, et al. [5] on the thermal properties of a pyrolysing wood particle. The specific heat capacities of the bulks wood increase as the temperature increases (i.e. specific heat capacities of the bulk wood are temperature dependent) which is in agreement with Simpson and Tenwolde [17] on the physical properties and moisture relations of wood. The results obtained are comparable to that Kärkkäinen [19] for an absolutely dry wood at temperature ranges of $273 \mathrm{~K}-373 \mathrm{~K}$. In Figure 3, density of the bulk samples increases with an increase with specific heat capacity between the ranges of $403.7 \mathrm{Kgm}^{-3}-405.1$ $\mathrm{Kgm}^{-3}$. There is sharp drop on the value of the specific heat capacity at $411.1 \mathrm{Kgm}^{-3}$. However, in Figure 4, density increases with an increase in specific heat capacity between the ranges of $391.6 \mathrm{Kgm}^{-3}-396.5 \mathrm{Kgm}^{-3}$ before it later increases with decrease in specific heat capacity.

Previous researches had also suggested that the specific heat capacity of wood has no practical dependence on density and species [10, 17].

Comparing the result with the thermal insulation property of some commonly used materials for photovoltaic layer properties which ranges between $0.2148 \mathrm{Wm}^{-1} \mathrm{~K}^{-1}$ $148 \mathrm{Wm}^{-1} \mathrm{~K}^{-1}$, all the values obtained were found to fall 


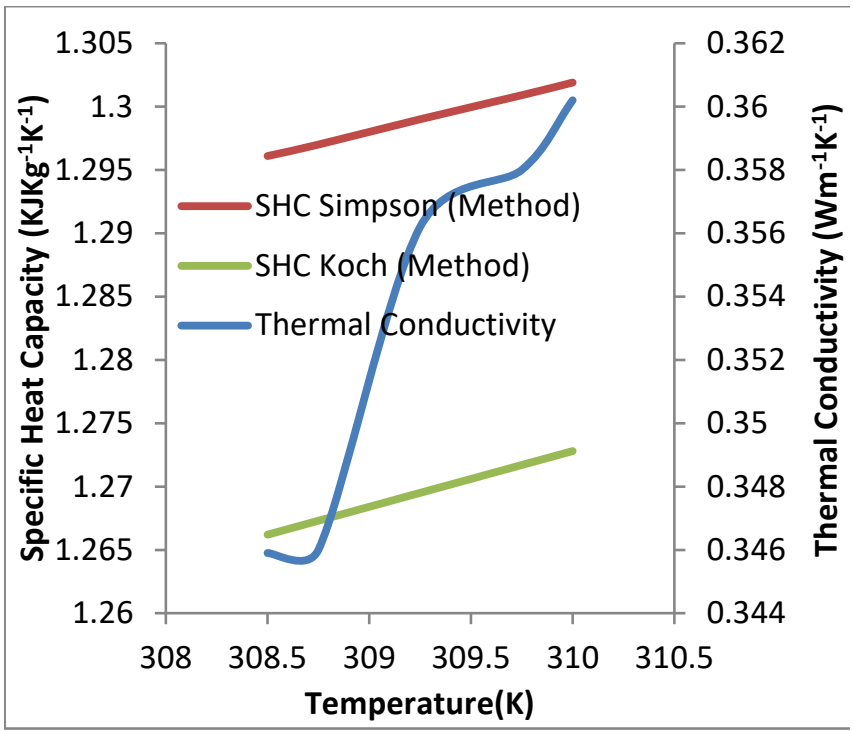

Fig. 2 Graph of Specific Heat Capacity $\left(\boldsymbol{k J} \boldsymbol{k g}^{-\mathbf{1}} \boldsymbol{K}^{\mathbf{- 1}}\right)$ and Thermal Conductivity $\left(W m^{-1} K^{-1}\right)$ against Temperature $(\mathrm{K})$ for Antiaris africana

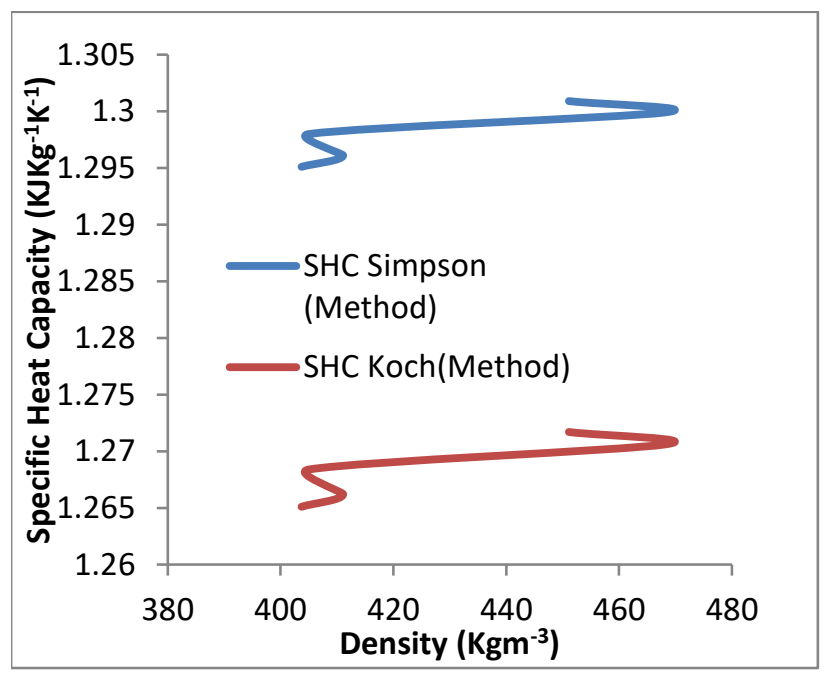

Fig. 3. Graph of Specific Heat Capacity $\left(\boldsymbol{k J} \boldsymbol{k g}^{-\mathbf{1}} \boldsymbol{K}^{-\mathbf{1}}\right)$ against Density $\left(\mathrm{Kgm}^{-3}\right)$ for Pterygota macrocarpa

within the established properties [20,21]. Hence, the materials can be utilized as thermal insulators in electronics and thermoelectric devices.

\section{CONCLUSION}

It was established in the research that temperature played significant role when considering thermal properties of wood materials. Thermal conductivity of wood samples increases with increase in temperature. The conductivity is directly proportional to the specific heat capacity of the bulk sample. Within the limit of this research, the thermal conductivities of the samples were found to be comparable to that of the materials used as industrial insulators. Hence,

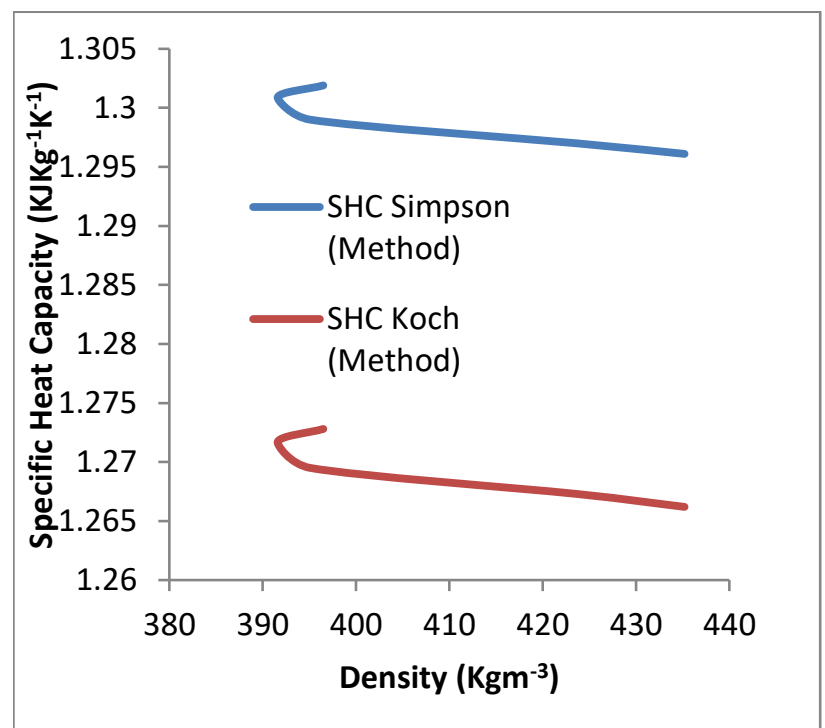

Fig. 4. Graph of Specific Heat Capacity $\left(\boldsymbol{k J} \mathbf{k g}^{-\mathbf{1}} \boldsymbol{K}^{\mathbf{- 1}}\right)$ against Density $\left(\mathrm{Kgm}^{-3}\right)$ for Antiaris africana

they could serve as useful materials in industrial insulating devices.

\section{REFERENCES}

[1] Adekoya, M.A., Oluyamo, S.S., Oluwasina, O.O. and Popoola, A. I. (2018). Structural Characterization and Solid-State Properties of Thermal Insulating Materials for Different Size Classifications. Bioresources 13(1), 906-917 https://doi.org/10.15376/biores. 13.1.906-917

[2] Oluyamo S. S. and Adekoya, M.A. (2021). Characterization of cellulose nanoparticles for materials device applications and development Materials Today: Proceedings, 38(2):595-598 https://doi.org/10.1016/j.matpr.2020.03.311

[3] TenWolde, A., McNatt, J. D. and Krahn, L. (1988). Thermal Properties of Wood and Wood Panel Products for Use in Buildings. Department of Energy, Oak Ridge National Laboratory. Oak Ridge, Tennessee, U.S., Pp 39.

[4] Yapici, F., Ozcifci, A., Esen, R. and Kurt, S. (2011). The Effect of Grain Angle and Species on Thermal Conductivity of Some Selected Wood Species. BioResources Technology, 6(3): 2757 2762

[5] Hankalin, V., Ahonen, T. and Raiko, R. (2009). On Thermal Properties of a Pyrolysing Wood Particle. In Finnish -Swedish Flame Day, January 28-29, 2009. Naantali, Finland, Pp 1- 16.

[6] Oluyamo, S. S. and Adekoya, M. A. (2015). Effect of Dynamic Compression on Thermal Properties of Selected Wood Products of Different Particle Sizes. International Research Journal of Pure and Applied Physics 3: 22-29.

[7] Şahin, K. H., Uysal, B., Kurt, Ş. and Ozcan, C. (2010). Thermal conductivity of oak impregnated with some chemicals and finished", BioResources Technology, 5(2): 545 - 555.[8] Grønli, M. G. (1996). Theoretical and experimental study of the thermal 
degradation of biomass. Doctoral dissertation. Trondheim. Norwegian University on Science and Technology, Faculty of Mechanical Engineering, Dept. of Thermal Energy and Hydropower. Norway. 339 p

[9] Ayugi, G., Banda, E. J. K. B. and D'Ujanga, F. M. (2011). Local Thermal Insulating Materials for Thermal Energy Storage. Rwanda Journal,

23

21-29.

[10] Oluyamo, S. S., Famutimi, O. F., Adekoya, M. A. and Aramide, T. M. (2016) Thermal Properties of Soil Samples from Coastal Sand Landform in Ilaje Local Government Area of Ondo State, Nigeria. Journal of Advances in Physics, 11(10): 4137-4140 https://doi.org/10.24297/jap.v11i8.193

[11] Duncan, M. P. and Mark, J. (2000) Thermal Conductivity of PTFE and PTFE Composites' IPTME. Loughborough University, Loughborough, UK. Pp. 580-581.

[12] Griffin, J. J. and George, J. (2002). Lees' Conductivity Apparatus (Electrical Method) LL44-590 I.S. 1122/7302, Griffin \& George Ltd., Wembley, Middlesex UK. Pp 2-4.

[13] Oluyamo, S. S., Bello O. R. and Yomade, O. J. (2012). Thermal Conductivity of Three Different Wood Products of Combretaceae Family; Terminalia superb, Terminalia ivorensis and Quisqualis indica, Journal of Natural Sciences Research, 2(4): $36-43$

[14] Oluyamo, S. S. and Bello, O. R. (2014). Particle Sizes and Thermal Insulation Properties of Some Selected Wood Materials
[15] Ekpe, S.D., Akpabio, L.E., and Eno, E. E (1996) Global Journal of Pure and Applied Science. 2 (1), 45-52.

[16] Akpabio, L.E., Ekpe, S.D., Etuk, S. E. and Essien, K. E. (2001). Global Journal of Pure and Applied Science., 7(3) 575-578. https://doi.org/10.4314/gjpas.v7i3.16290

[17] Simpson, W. and TenWolde, A. (1999). Physical Properties and Moisture Relations of Wood in: Wood Handbook: Wood as an engineering material. Gen, Tech. Rep. FPL-GTR-113, Department of Agriculture, Forest Service, Forest Products Laboratory, Madison, U.S, Pp. 15 - 22 (Chapter 3).

[18] Gupta, M., Yang, J. and Roy. C. (2003). Specific heat and thermal conductivity of softwood bark and softwood char particles. $\begin{array}{llll}\text { Fuel. Vol. } & \text { 82, } & \text { pp. } & \text { 919-927. }\end{array}$ https://doi.org/10.1016/S0016-2361(02)00398-8

[19] Kärkkäinen, M. (2007). [Structure and Properties of Wood] Puun rakenne ja ominaisuudet. Metsäkustannus Oy. Karisto Oy, Hämeenlinna. 468 p. In Finnish .

[20] Lu, Z.H and Yao, Q. (2007). Energy Analysis of Si Solar Cell Modules Based on an Optical Model for Arbitrary Layers. Solar Energy, 81, 636-647 .https://doi.org/10.1016/j.solener.2006.08.014

[21] Armstrong, S., Hurley, W.G. (2010). A thermal model for Photovoltaic Panels under Varying Atmospheric Conditions. Applied Thermal Engineering, 30, 1488-1495 https://doi.org/10.1016/j.applthermaleng.2010.03.012 